\title{
Idosos Encarcerados: Trajetória de Vida à Luz da Teoria da Memória Coletiva
}

\author{
Incarried Elderly: Life Path in Light of the Theory of Collective Memory
}

Mayor Encargado: El Camino de la Vida a la Luz de la Teoría de la Memoria Colectiva

\section{Pollyanna Viana Lima}

Faculdade Independente do Nordeste (FAINOR), Vitória da Conquista, BA, Brasil

\author{
Tatiane Dias Casimiro Valença
}

Alessandra Souza de Oliveira

Luciana Araújo dos Reis

Universidade Estadual do Sudoeste da Bahia (UESB), Vitória da Conquista, BA, Brasil

\begin{abstract}
Resumo
O estudo tem por objetivo conhecer a trajetória de vida de idosos encarcerados antes e na prisão à luz da teoria da memória coletiva/social. Estudo exploratório e descritivo, com abordagem qualitativa, triangulação de método, fundamentado na Teoria da Memória Coletiva/Social e das Representações Sociais. Realizado em três unidades penais da Bahia com 31 idosos, com 60 anos ou mais, que se encontravam em situação de cárcere. Foram utilizados quatro instrumentos: questionário para coleta de dados nos prontuários de saúde, de assistência social e psicologia; entrevista semiestruturada; grupo focal; e observação não participante com uso de diário de campo. Vimos que a trajetória de vida de idosos encarcerados antes e na prisão preserva a constituição família e que há uma memória preservada das vivências geradoras da prisão e da insatisfação frente ao ambiente na prisional.
\end{abstract}

Palavras-chaves: Idosos; Cárcere; Memória; Representações Sociais.

\begin{abstract}
The study aims to understand the life trajectory of elderlyin carcerated beforeand in prison in light of the theory of collective/social memory. Exploratory and descriptive study, with a qualitative approach, method triangulation, based on the Theory of Collective/Social Memoryand Social Representations. Carried out in three penal units in Bahia with 31 elderlypeople, aged 60 yearsor more, whowere in prison. Four instruments were used: a question naire to collect data from health, social assistance and psychology records; semistructured interview; focus group; and non-participant observation using a field diary. We saw that the life trajectory of the elderlyin carcerated before and in prison preserves the family constitution and that there is a preserved memory of the experiences that generate prison and of dissatisfaction with the prison environment.
\end{abstract}

Keywords:Elderly; Prison; Memory; Social Representations. 


\section{Resumen}

El estudiotiene como objetivo comprender la trayectoria de vida de los ancianos encarcelados antes y en prisión a la luz de la teoría de la memoria colectiva / social. Estudio exploratorio y descriptivo, con enfoque cualitativo, método de triangulación, basado em la Teoría de la Memoria Colectiva / Social y Representaciones Sociales. Realizado entres unidades penales de Bahía con 31 ancianos, de 60 años o más, que se encontraban en prisión. Se utilizaron cuatro instrumentos: um cuestionario para recopilar datos de los registros de salud, asistencia social y psicología; entrevista semi-estructurada; grupo de enfoque; y observación no participante utilizando un diario de campo. Vimos que la trayectoria de vida de los ancianos encarcelados antes y en la cárcel preserva la constitución de la familia y que hay un recuerdo preservado de las vivencias que generan la prisión y de la insatisfacción con el ambiente carcelario.

Palabras clave:Anciano; Prisión; Memoria; Representaciones sociales.

\section{Introdução}

No âmbito do encarceramento do idoso, as discussões a respeito da relevância social da memória e das representações sociais tornam-se notadamente significativas, uma vez que as acepções humanas estão introduzidas em um contexto social. Nesse sentido, é importante frisar o caráter transversal da memória coletiva/social e das Representações Sociais no diálogo multidisciplinar e as inúmeras possibilidades de aplicação aos mais diferentes objetos de estudo, nesse caso, a pessoa idosa encarcerada.

Por entender que esse objeto é um tanto complexo, mas, ao mesmo tempo, possível de ser compreendido por meio de acepções sociais, o nosso estudo foi fundamentado sobre os construtos teóricoconceituais da Memória Coletiva/Social, articulando com a fundamentação da teoria psicossocial das Representações Sociais de Serge Moscovici, na perspectiva da abordagem processual ou culturalista de Denise Jodelet.

As duas teorias supracitadas possuem divergências, mas também inúmeras semelhanças. Foram justamente as semelhanças que nos proporcionaram o interesse para a realização deste estudo, pois acreditamos que tanto a Teoria da Memória como a Teoria das Representações Sociais possuem elementos importantes para identificar os aspectos socioculturais que ajudarão a explicar de 
forma mais concreta acerca da situação do idoso encarcerado.

Entre as semelhanças, é conveniente destacar a relação com o meio social; a origem epistemológica presente nos pressupostos de Émile Durkheim (1958 - 1917); a dependência dos processos comunicacionais; as evocações das lembranças, pois estas sofrem influências do presente; o passado, que é reatualizado conforme a posição que o sujeito ocupa na sociedade; a memória, que é elaborada na experiência dos indivíduos, vivenciada em grupo, sendo um elemento da consciência de extrema importância na elaboração das representações, e, por fim, o fato de ocorrer uma semelhança entre a memória social e os processos de ancoragem nas representações sociais.

A memória é elaborada na experiência dos indivíduos, vivenciada em grupo, além disso, é um elemento da consciência de extrema importância na elaboração das representações. As recordações dos idosos encarcerados representaram traços dessas experiências de vida. Para tanto, podemos dizer que a elaboração dos relatos foi a consagração da memória dos idosos encarcerados, e, esta, sem dúvida, acontece submersa em toda uma carga de experiências, pois "as lembranças são reconstruções que se Rev. Polis e Psique, 2021; 11(3): 138 - 159 apoiam no passado, mas orientadas em função de necessidades e interesses do presente. Seus conteúdos nunca são reproduções do passado, mas representações construídas a partir deste" (Pecora e Sá, 2008).

Acreditamos ainda que os idosos encarcerados expressaram os seus valores, o simbolismo, os costumes, as regras de regulação social na instituição prisão, reconstruindo e representando a memória coletiva a partir de suas vivências e experiências do ponto de vista do grupo de idosos submetidos ao espaço prisional, lugar de onde reconstruíram o passado no presente. Nesta perspectiva, o presente estudo tem por objetivo conhecer a trajetória de vida de idosos encarcerados antes e na prisão à luz da teoria da memória coletiva/social.

\section{Metodologia}

Trata-se de um estudo caracterizado como exploratório e descritivo, com abordagem qualitativa, e tem como aporte teórico-metodológico a Memória Coletiva e a Teoria das Representações Sociais. O estudo foi realizado em três Unidades Prisionais (UP) do interior da Bahia. As UP custodiam presos provisórios e condenados, dando cumprimento às penas 
privativas de liberdade. A Unidade Prisional 1 (UP1) e a Unidade Prisional 2 (UP2) atendem aos Regimes Fechado, Semiaberto e Provisório, já a Unidade Prisional 3 (UP3) atende apenas aos Regimes Fechados e Regime Provisório. Os participantes do presente estudo foram representados por 31 pessoas com 60 anos ou mais que estavam aptas para participar da pesquisa, pois se encontravam em situação de cárcere, alojadas em um dos Conjuntos Penais selecionados para realização da pesquisa e que tinham cognitivo preservado, avaliado pelo MiniExame do Estado Mental (MEEM).

Em nosso estudo, optamos pela triangulação de métodos sobre um mesmo objeto, no intuito de tornar mais persuasivas e precisas as informações obtidas (Prodanov \& Freitas, 2013). Foram utilizados quatro instrumentos: um questionário para coleta de dados nos prontuários; um roteiro para o grupo focal; um roteiro para entrevista semiestruturada e observação participante.

O questionário para coleta de dados nos prontuários de saúde, de assistência social e psicológica teve perguntas envolvendo questões demográficas, psicossociais e epidemiológicas. A entrevista foi baseada em um roteiro que apresentou questões sobre as recordações Rev. Polis e Psique, 2021; 11(3): 138 - 159 na prisão e antes da prisão, com o intuito de conhecer as memórias dos idosos encarcerados. Já o grupo focal teve como objetivo apreender as Representações Sociais dos idosos encarcerados sobre a Velhice e Saúde na prisão por meio de suas memórias.

$\mathrm{O}$ registro dos dados ocorreu por meio de gravação, mas, devido ao fato de muitos idosos terem dicção ruim e/ou falarem baixo, foi preciso fazer a tomada de nota, para a qual contamos com o apoio da assistente social, que, prontamente, dispôs-se a contribuir em todo o processo dos grupos. Os grupos focais tiveram duração máxima de uma hora e ocorreu sempre junto com a profissional da assistência social e da psicologia, as quais tornavam-se as relatoras.

O diário de campo foi utilizado para registrar as impressões e informações sobre como chegamos ao campo, como era o campo e as relações cotidianas vistas nele. Vale destacar que, no momento das anotações, não tínhamos a ideia de que tudo o que fosse escrito no diário de campo seria um dado científico, visto que as categorias analíticas emergiram das informações coletadas pelas entrevistas e o grupo focal a partir de uma reflexão teórica.

A entrevista semiestruturada assim 
como os resultados do grupo focal foram analisados por meio da técnica de Análise de Conteúdo descritos por Laurence Bardin, na modalidade de análise temática (Bardin, 2015). Essa pesquisa foi aprovada pelo Comitê de Ética em Pesquisa da Universidade Estadual do Sudoeste da Bahia com parecer $\mathrm{n}^{\circ}$ 1.968.281.
Concentramo-nos sobre os relatos dos entrevistados acerca da sua vida antes e na prisão com ênfase em suas experiências vivenciadas no cárcere, a partir da análise de conteúdo temático. O corpus foi formado a partir de 812 unidades temáticas, que foram organizadas em uma classe temática e três categorias, conforme é apresentado no Quadro 1.

\section{Resultados e discussão}

Quadro 1 - Eixo temático e categorias analíticas sobre as memórias de idosos encarcerados antes da prisão e na prisão, Bahia, 2021.

\begin{tabular}{|l|l|l|}
\hline EIXO TEMÁTICO & N & CATEGORIAS \\
\hline $\begin{array}{l}\text { Memória e representações sociais de idosos } \\
\text { encarcerados: considerações iniciais }\end{array}$ & 257 & $\begin{array}{l}\text { Categoria 1. Memórias de idosos } \\
\text { encarcerados sobre família }\end{array}$ \\
\hline Total das unidades temáticas & 555 & $\begin{array}{l}\text { Categoria 2. Memórias de idosos } \\
\text { encarcerados sobre o ambiente prisional }\end{array}$ \\
\hline
\end{tabular}

Fonte: Elaboração própria.

Categoria 1. Memórias de idosos encarcerados sobre família

A família mantém-se porque as experiências que nela são simbolizadas têm como referência definições cristalizadas que são socialmente construídas pelos dispositivos jurídicos, mas também médicos, religiosos, psicológicos e pedagógicos (Sarti, 2004). Talvez por isso se explique o fato de os idosos que se encontram em situação de cárcere, mesmo distantes fisicamente e/ou emocionalmente, terem uma relação forte com a família, seja ela carregada de recordações positivas ou mesmo negativas.

Como diz o participante 10, "Quando se trata de família, para mim é fator primordial. Tudo começa pela família. A minha existência é minha 
família”. Essa fala do idoso direciona-nos a pensar a "família como algo que se define por uma história que se conta aos indivíduos, ao longo do tempo, desde que nascem, por palavras, gestos, atitudes ou silêncios, e que será por eles reproduzida e ressignificada, à sua maneira” (Sarti, 2004, p. 26).

Nesse sentido, trilhamos nossas análises dessa categoria em torno da família mais próxima e dos relacionamentos em que os idosos estão envoltos por meio de trechos de suas narrativas.

Família é a minha base. A razão da minha existência são meus pais. Eles só têm eu de filho. (IE-09)

Conforme os trechos das falas dos idosos acima descritos, a família é a base, o ponto de referência para as suas vidas. Maurice Halbwachs, em seu livro "Les Cadres Sociaux de la Mémoire”, já salientava o papel da família como constituição primeira, o ponto de referência para uma pessoa, pois, somente a partir de um quadro, nesse caso, o familiar, é possível reconstruir a imagem das pessoas e dos fatos (Halbwachs, 1994).

É justamente pelo fato de os idosos terem uma relação de pertencimento no grupo familiar que eles trazem em seus relatos a saudade que, ora sofrem, ora os Rev. Polis e Psique, 2021; 11(3): 138 - 159 torna fortes para permanecerem vivos $\mathrm{e}$ buscarem uma mudança de vida.

Sinto mais saudade dos meus filhos e da minha mulher. Quero muito sair daqui e poder estar com eles. (IE-03)

Nos relatos que se seguem, outro ponto que foi evidenciado foram as contradições sobre as famílias, pois as narrativas dos idosos representaram perdas, rupturas, mortes, separação e tristeza.

Já bati na minha filha, com talo de capim, que quase mato minha filha, e hoje é ela que cuida de mim. Fico triste com isso e, às vezes, choro. (IE-16)

O que fica evidenciado nas falas é uma fragilidade nos vínculos familiares, bem como a existência de violência, dois pontos que juntos ou mesmo individualmente têm repercussões nas vidas dos indivíduos. Sobre isso, os estudos têm demonstrado que a convivência em ambientes familiares onde a violência impera e onde existe uma fragilidade nos vínculos aumenta a probabilidade de os indivíduos serem vítimas de violência, mas, principalmente, praticarem-na, o que pode ser uma questão cultural que é naturalizada no ambiente familiar (Zappe \& Dias, 2012; Cronemberger \& Teixeira, 2013).

De maneira geral, os idosos participantes do estudo relataram sobre a 
família com um olhar positivo e, apesar de estarem em situação de reclusão e de terem em suas memórias recordações sobre a instituição familiar, por vezes, conflitantes e contraditórias e com fragilidades de vínculos, a família, ainda assim, é o marco de equilíbrio na vida dos idosos encarcerados.

Categoria 2. Memórias no Ambiente Prisional

Ao rememorarem situações vividas relacionadas à prisão, alguns idosos trouxeram em suas recordações não apenas momentos vivenciados na prisão, mas também de como chegaram até ela, como se deu o crime e como ocorreu a prisão. Bem por isso o título desse eixo temático, "Memórias no Ambiente Prisional", foi definido no sentido de aludir às memórias que os idosos têm, estando inseridos nesse ambiente.

As memórias dos idosos reconstruídas do espaço prisional possibilitaram rememorações sobre a prisão; vida na prisão; ambiente prisional; o crime; a inocência e a fuga do crime; a droga e o tráfico; a violência na prisão; a relação entre os presos; o arrependimento, o grupo de idosos; a religião; os estigmas e as dificuldades de inserção na sociedade.
Acreditamos que as narrativas que se seguem são características de uma memória coletiva que pode estar ligada tanto à memória de todos os membros de uma sociedade (Fentress \& Wickham, 1992) quanto a de grupos sociais no seu interior (Halbwachs, 2013). Nesse sentido, as memórias dos idosos encarcerados sobre o ambiente prisional não se direcionam e, muito menos, restringem-se apenas a narrar recordações de um grupo, mas também situações que envolvem todo um contexto social.

O relato dos idosos está muito relacionado ao modo como a prisão é constituída e à forma como o seu ambiente é projetado. Por isso, coadunamos com Onofre (2016) que, enquanto a pena privativa perdurar da forma como vem sendo conduzida, caracterizada como intervalo de tempo, com interrupção do percurso de vida, como uma descontinuidade e feita apenas para punir, será impossível ouvir relatos positivos.

A vida na prisão é difícil. Dizem que isso é feito para ser humano, mas não acredito. Aqui é muita discriminação das pessoas que trabalham como cozinheiro, na limpeza. (IE-10)

Essa dúvida relatada, especialmente na narrativa do IE-10, é reflexo do que lhes é apresentado e vivenciado no dia a dia na 
prisão, pois não há como ser diferente com um sistema prisional que lhes permite, além da ruptura com a sociedade, um ambiente inadequado, inóspito, insalubre, com condições mínimas de sobrevivência, conforme pode ser percebido no trecho do relato que se segue:

Aqui a gente dorme no chão, nuns colchões duros e finos, isso quando acha colchão, porque a gente faz revezamento. (IE-01)

De acordo com Soares Filho e Bueno (2016, p.2000), a população encarcerada brasileira vive abaixo da linha de dignidade mínima, não sendo a ela garantidos, malgrados declarados, seus primordiais direitos; em particular, aquele que poderia lhe conferir uma convivência saudável, no plano de um "mínimo existencial". O mencionado por esses autores pôde ser ouvido dos entrevistados e visto pela pesquisadora nas UP, além de ser confirmado pelo resultado das inspeções estaduais do Conselho Nacional de Justiça na Bahia no ano de 2017 (CNJ) (Brasil, 2018).

Outro ponto que nos chamou a atenção refere-se ao ambiente em que os idosos dormiam, pois, praticamente, todos relatavam que havia poucos colchões e eram muito finos. $\mathrm{O}$ revezamento era uma constância, e eles destinavam aos mais Rev. Polis e Psique, 2021; 11(3): 138 - 159 doentes e aos que tinham problemas de coluna. Porém, problemas ou, ao menos, queixas de sintomas na coluna eram uma queixa de quase a totalidade dos idosos. Os dois trechos selecionados são extremamente representativos do aqui descrito.

Aqui a gente dorme no chão, nuns colchões duros e finos, isso quando acha colchão, porque aqui a gente faz revezamento. (IE-01)

Além de dormir no chão, os idosos precisam conviver com o ambiente frio, o que facilita o desenvolvimento de doenças. Era uma queixa de quase todos, principalmente na UP3, o fato de terem apenas roupa de calor (uma bermuda e uma camiseta de manga curta) e terem que conviver com um frio constante.

A alimentação foi uma das queixas mais evidenciadas pelos idosos encarcerados, o que lhes provocava raiva e revolta. De acordo com o Art. 13 da Resolução n. ${ }^{\circ}$ 14/94 do Conselho Nacional de Política Criminal e Penitenciária (CNPCP, 1994), tanto a quantidade de alimentos nas refeições por dia quanto a qualidade devem ser garantidas aos indivíduos que se encontram em reclusão: “A alimentação será preparada de acordo com as normas de higiene e de dieta, controlada por nutricionista, devendo 
apresentar valor nutritivo suficiente para manutenção da saúde e do vigor físico do preso". Assim também, o Plano Nacional de Saúde no Sistema Penitenciário (PNSSP) define como ação de promoção da saúde o fornecimento de alimentação de qualidade adequada. Entretanto, na prática o que vimos pode se resumir neste relato que se segue.

Aqui a refeição é ruim, a comida é ruim demais, sem tempero, sem nada, sem gosto. (IE-08)

Sendo assim, o que é apresentado na teoria está longe de ser concretizado. Essa percepção não foi somente dos entrevistados, mas também das pesquisadoras, que, apesar de não terem acesso direto à comida servida, podiam visualizar a forma como era servida e a sua aparência. Destacamos que não era muito agradável o que vimos; por esse fato, entendemos a revolta com que falavam da alimentação, especialmente da UP1.

Isso aqui que oferece para nós parece mais uma ração, além de ser feia, é sem gosto, o feijão parece que só tem água. (IE-11)

$\mathrm{O}$ aqui apresentado sobre $\mathrm{O}$ ambiente da prisão não é muito diferente dos resultados de outros Estados do Brasil, como pode ser visto na conclusão da autora Minayo sobre o ambiente das prisões do Rio de Janeiro. Nelas os homens e Rev. Polis e Psique, 2021; 11(3): 138 - 159 mulheres queixam-se das condições de cela superlotada, o dormir no chão, roupas de cama e colchões imundos e malcheirosos, colchões e camas inadequadas, a falta de lençóis e cobertores, contato direto com insetos e animais peçonhentos, banheiros quase sempre entupidos, falta de privacidade para as necessidades e comidas ruins (Minayo, 2015).

\section{Sobre as memórias do crime}

A narrativa que se segue apresenta duas problemáticas: a primeira, a violência contra mulher, e a segunda, o alcoolismo, fatos recorrentes em noticiários, especialmente o primeiro, e pauta de inúmeros debates na academia. A violência contra a mulher tem sido considerada um problema de saúde pública e de direitos humanos (Opas, 2015) com inúmeros impactos para a sociedade e para as vítimas, uma vez que esta pode gerar sofrimentos irreparáveis na vida, sejam eles de ordem física ou mental.

$\mathrm{Eu}$ estava bebendo, mas estava consciente... Na hora foi assim, empurrei ela, e ela caiu. Tive um momento de descontrole e acabei espancando a minha mulher, que sempre foi tão boa para mim. A polícia chegou e me trouxe. (IE-03) 
Ao analisarmos esse pequeno relato, mas carregado de complexidade, percebemos que, ao rememorar o fato, o idoso mostra arrependimento, mas, ao mesmo tempo, deixa claro que a violência, de alguma forma, já ocorria. O alcoolismo associado a outros fatores sociais e culturais tem sido um dos maiores provocadores de violência doméstica. Almeida (2009), Fals-Stewart (2003) e Laranjeira, Duailibi e Pinsky (2005) corroboram o dito, uma vez que seus estudos demonstraram que o álcool é um facilitador do processo, influencia no comportamento violento, e existe uma relação complexa entre a violência e álcool a ser investigada.

Outra problemática anunciada no trecho da narrativa do IE-03, que se segue, é a questão da dependência do álcool entre os idosos. Assim como o crescimento da população idosa no Brasil, as problemáticas associadas estão também aumentando, entre elas, o consumo tido como "social" do álcool, mas também o abusivo, cuja dependência torna-se uma doença.

Não gosto muito de falar porque fui preso. Não fiz nada, trabalhava na roça a minha vida toda, só tomava umas cachacinhas no fim de semana no bar. (IE-26)
Ainda pautada nas discussões sobre a violência contra mulher, a narrativa que se segue apresenta outra questão emblemática entorno da violência ora já apresentada. Estamos diante de uma narrativa que rememora a violência contra a mulher, construída por explicações, mas entremeada por um dos fatores desencadeadores e mantenedores da violência, que é a questão de gênero, e pautada no histórico patriarcado.

Vim para a prisão por conta de uma traição de minha mulher. Ela já estava me traindo há mais de dois anos [...] Aí veio uma coisa muito ruim naquela hora, pensei muita besteira, veio aquela loucura... Mas eu estava de cabeça quente e aí, quando vi ela no colégio, voltei, fui no mercado próximo ao colégio, comprei uma faca e fui lá e fiz o que fiz. Ela (esposa) ficou 20 dias no hospital, não morreu na hora, ficou sofrendo 20 dias e não resistiu [...] (IL-20)

A narrativa desse idoso traz à discussão os inúmeros casos de violência no Brasil que têm como fim a morte da mulher (Barufaldi et al., 2017), algo que inquieta a sociedade e nos faz também questionar os porquês da permanência da violência da mulher no Brasil. Acosta et al. (2015, p.123) destaca que "a naturalização do poder masculino sobre o corpo e as escolhas da mulher, fruto dos estereótipos 
culturais, tem servido para legitimar a prática da violência doméstica"; assim como esses autores, entendemos também que esse pode ser um dos motivos para a perpetuação da violência.

A seguir apresentaremos os crimes cometidos por idosos, mas agora voltados à violência sexual contra vulneráveis, nas quais, mais uma vez, a mulher enquanto menina, criança é vítima, conforme poderá ser visto nas narrativas abaixo.

Coisas de política, porque eu não votei, aí me arrumaram um embargo lá e me botou aqui. Eles me acusaram de levar a menina para algum lugar, de alisar a menina, uma menina de 10 anos que eu levava para escola junto com minha filha. (IE-14)

Os crimes sexuais que têm como vítima uma pessoa vulnerável, de uma maneira geral, despertam repúdio e ódio na sociedade. Essa realidade não é destoante dentro da prisão, pois foi percebido na prática que o tratamento para esses homens era diferente em comparação aos demais que estavam enquadrados em outros artigos. Percebemos que nas UP onde ocorreram a pesquisa, os homens que cometiam crimes sexuais, em especial o de vulneráveis, ficavam em celas destinadas à triagem, já que não existia uma cela específica para esses homens; cela esta que serviria apenas de passagem para todos que Rev. Polis e Psique, 2021; 11(3): 138 - 159 ali chegavam, para, posteriormente, irem para as definitivas, e que os enquadravam.

Outro crime cometido por idosos que foi rememorado refere-se ao tráfico, o qual, para a maioria, foi iniciado com o uso de drogas. O uso de substâncias psicoativas por idosos tem aumentado no Brasil, sendo o álcool a droga mais comum, mas outras têm sido frequentemente utilizadas, como o abuso de medicamentos e de substâncias ilícitas, dentre as quais se destacam a maconha e a cocaína (Pillon et al., 2010, Cruz et al., 2016).

Nesse sentido, as memórias dos idosos retratadas nas narrativas abaixo chamam a atenção para essa problemática, que começou a ser apresentada anteriormente, quando foi relatado por alguns idosos o uso de álcool, corroborando os estudos supracitados. Já nos trechos que se seguem, alguns idosos relataram a vivência com a droga desde a juventude e que ela foi o estopim para, posteriormente, envolverem-se com o tráfico.

Foi a droga que me trouxe para a prisão, eu usava, eu compartilhava, eu vendia. Sempre me pergunto porque estou aqui. (IE-24)

Ao analisarmos as narrativas, foi possível perceber os efeitos das drogas na vida desses idosos, sejam eles econômicos, 
sociais ou físicos. Quando se trata das questões físicas, é pertinente mencionar que todos esses idosos encontravam-se extremamente debilitados, magros e com inúmeras patologias, entre elas, a tuberculose.

Outros crimes emergiram nos relatos dos idosos, entre eles, o homicídio, roubo, falsidade ideológica, estelionato, conforme podem ser vistos a seguir:

Já fui preso duas vezes por causa da mesma coisa, porque roubei caminhão. A pessoa fica com ganância das coisas, querer ter as coisas de qualquer jeito. (IE15)

Frente a tantos crimes relatados e rememorados pelos idosos, emergiram aqueles que preferiram esquecer das memórias do crime e relatar a inocência. Não nos cabe duvidar dos momentos de memórias descritas e revividas, mas apresentar e analisar os relatos. Além disso, é pertinente relatar que, frente à convencionalização, as memórias sobre o crime postas pelos indivíduos participantes deste estudo podem permanecer intactas, ser transformadas ou, ainda, ser esquecidas (Bartlett, 1995).

Nesse sentido, foi possível observar que a maioria dos participantes do estudo que rememoraram a inocência fizeram-no relacionando-a aos crimes sexuais, talvez pelo fato de ser esse um crime inaceitável pela sociedade e/ou que, de alguma forma, trouxe tristeza para eles ao relatarem, o que provoca uma vontade constante de esquecimento. Os momentos de rememoração sobre os crimes, especialmente os sexuais, foram os que mais provocaram tristeza e vergonha e demonstram a dificuldade de recordar o momento.

Eu fui acusado de uma coisa que eu não fiz. Me acusaram de molestar a sobrinha de minha companheira de sete anos, e a polícia me prendeu. Disse que eu fiz uma coisa com ela que não fiz. (IE-28)

Essa negação do passado pode ser um ato voluntário ou mesmo involuntário da memória (Halbwachs, 2013) desses indivíduos, que podem ser caracterizados pela fuga do crime e da realidade objetiva na qual estão inseridos. Para tanto, ao buscarem esquecer o momento da prisão ou o que levou a ela, de certa forma, esses indivíduos não querem dar um significado (Bartlett, 1995) para ele.

\section{Sobre a violência na prisão}

Apesar de apenas dois idosos rememorarem momentos de violência na prisão de forma direta, ao longo dessa subcategoria, podem ser vistas várias 
formas de violência, porém aqui selecionamos apenas três que se caracterizam como a violência física ou mesmo a ameaça para que ela ocorra.

Quando eu fui transferido para cá, me colocaram lá no outro pavilhão, não estava na triagem. Me colocaram lá junto com criminosos da pesada. Só porque eu disse que era inocente, que não matei ninguém, eles acharam que eu tinha cometido um outro crime, me chamaram de mulherzinha (IE-10)

Segundo Machado (2013), o ambiente da prisão é propício à violência física, a qual pode ser sob forma de torturas e assassinatos ou como forma punitiva em desrespeito aos mínimos direitos dos presos. A violência física, assim como qualquer outro tipo de violência, infringe os direitos humanos e demonstra a fragilidade da legislação brasileira (Gomes, Kölling \& Balbinot, 2015).

Os direitos humanos, são os direitos fundamentais que a pessoa humana tem, entre eles, $\mathrm{o}$ direito à vida, à alimentação, à saúde, à moradia e à educação (BRASIL, 1988). Todavia, devido não só à violência física, mas à psicológica e àquela que infringe o que é definido por lei, dificilmente esses direitos serão cumpridos dada a forma que o Rev. Polis e Psique, 2021; 11(3): 138 - 159 sistema carcerário no Brasil encontra-se, uma vez que ele tem sido um intensificador dessa violência (Gomes,Kölling eBalbinot, 2015; Andrade e Ferreira, 2015).

Sobre o convívio e as relações entre os presos

Percebemos que a prisão tem efeitos diferentes para as pessoas. Alguns, mesmo passando por sofrimento, saudade e dor, ficam à vontade na prisão, conseguem rir, conversar com os colegas de cela e com os agentes penitenciários. Já outros ficam sucumbidos na solidão, no desespero, no medo e no afastamento das relações interpessoais e se utilizam da prisão para pensar na vida e repensar o que fizeram.

A prisão é um inferno, mas de tudo na vida a gente tira proveito. (IE-09)

Apesar da diferença de adaptação na prisão, seja para aqueles que se “acostumaram” ou que ainda não, a relação entre eles é inevitável, com a qual é preciso aprender a conviver. De acordo com as narrativas dos participantes, eles procuram ter uma boa relação com todos e relatam que, por estarem em um módulo mais tranquilo ou em uma triagem, não têm muitos problemas, mas que precisam ter respeito para conviver em um lugar como a prisão. Ao que parece, existe uma memória dentro da prisão que é transmitida entre os 
presos, a de que o respeito deve ser a conduta no ambiente prisional para que um indivíduo consiga conviver de modo mais pacífico.

Minha relação com os outros presos é boa, eu respeito eles, e eles me respeitam, e todos me tratam bem. (IE-07)

De fato, foi notório, ao caminharmos pelas UP e conversarmos com alguns idosos encarcerados, que muitos agiam como se não estivessem ali, viviam submersos em um mundo que não era o de todos, isolados dentro deles mesmos. Talvez isso possa ser caracterizado como uma válvula de escape ou mesmo uma forma de manter a sobriedade.

\section{Sobre os grupos para idosos na prisão}

O equilíbrio é uma das formas de condução, a qual um indivíduo, quando entra na prisão, precisa adquirir, tendo em vista que esse é um lugar onde ninguém gostaria de estar, por ser inóspito, muitas vezes, inabitável e que, por si só, é provocador de preconceitos dentro da sociedade. Nesse entendimento, coadunamos com Sequeira (2005) quando relata a visão da prisão por meio de memórias de pessoas encarceradas.
Dessa forma, efetivamente, a vida desses indivíduos que se encontram reclusos é arrebatada, e suas relações são interrompidas. Viver de forma normal na prisão seria uma utopia, mas é justamente por esse fato que meios para amenizar essa realidade precisam ser construídos, com o intuito de possibilitar uma vida menos sofrida, com mais humanidade.

Assim sendo, tendo em vista essa realidade em que os idosos estão inseridos e as adversidades que a velhice impõe, os grupos de idosos são possibilidades para amenizá-la. Em duas UP, das três que adentramos, existiam esses grupos. Em uma, era organizado pelos profissionais da assistência social e da psicologia, e, em outra, da psicologia apenas. Percebemos que empenhos individuais têm possibilitado alguma humanização dentro da prisão e devem ser seguidos como exemplo.

Segundo os profissionais que lideravam os grupos de idosos na prisão, os grupos tinham objetivos, de certo modo, diferentes do que ocorria extramuros do sistema carcerário, uma vez que se trata de possibilitar minimamente a garantia de direitos de uma forma mais digna e, ao mesmo tempo, permitir que esses indivíduos tenham espaço de escuta e de socialização. Como não encontramos 
estudos que relatem a construção desses tipos de grupos em conjunto penal, não foi possível apresentar outras realidades. O que podemos demonstrar é, a partir das narrativas dos idosos, a importância desses grupos para eles.

A reunião aqui me fortalece, me faz sentir homem de novo. Aguardo ansioso para a reunião de 15 em 15 dias, eu e meus colegas [...]A reunião também é boa para a gente conversar, encontrar com os colegas, distrair um pouco, e a gente marca alguns exames também. (IE-22)

As narrativas dos idosos possibilitam perceber o quanto o grupo realizado nas duas UP é importante para os idosos e como fortalece e permite encarar a prisão com mais leveza. Além desses relatos por meio das entrevistas, podemos perceber na vivência a empolgação no momento em que eram chamados para a reunião. Era uma unanimidade o prazer, a alegria, o envolvimento e a gratidão por estarem na reunião. Além disso, há de se destacar o papel das profissionais envolvidas no grupo, um trabalho de dedicação e de desprendimento, mesmo diante de tantos entraves.

\section{Sobre a religião nas prisões}

A religião adentra-se nas prisões acolhendo, perdoando, transformando a realidade social, controlando motins e convertendo os indivíduos para recuperar espíritos, enquanto a prisão foi pensada para punir e criar algumas mínimas condições para recuperar cidadãos (Quiroga, 2012). A religião é transmitida e permanece, por meio de uma memória coletiva/social; a fé é revitalizada e revivida pelas cerimônias e acontecimentos religiosos, mas isso só ocorre porque a reconstrução do passado religioso, vivido e experimentado, decorre da influência do grupo (Halbwachs, 2013). O grupo aqui descrito é aquele de religiosos, seja de qual for a religião que adentra as UP e leva a memória da fé e a salvação para aqueles "pecadores".

Devido ao fato de a inserção da religião ser definida em lei e a ressocialização promovida pelo Estado não estar sendo efetivada como deveria, a religião toma força, cresce e tem demonstrado resultados positivos concretos, mesmo diante de críticas e polêmicas estabelecidas (Novaes, 2012; Minayo, 2015).

Nas três UP em que realizamos a pesquisa, a presença da religião não foi diferente. Muitos depoimentos demonstraram o seu comparecimento 
contínuo e a efetividade de ações para busca de "salvação" e consequente reinserção daqueles indivíduos em sociedade. Os relatos apresentados abaixo demonstram essa realidade:

É a religião que está me salvando aqui. Tenho fé que vou sair dessa. Me converti aqui dentro, hoje sou evangélico. (IE-24)

Como pode ser visto nas narrativas acima descritas, duas religiões cristãs estão predominantemente presentes nas três UP em que realizamos o estudo, com destaque para a religião evangélica. Neste presente estudo, todos os 31 idosos declararam praticar alguma religião, sendo a evangélica a maioria, seguida da católica. Estudos têm demonstrado que as igrejas evangélicas estão mais presentes no contexto prisional; as católicas estão em menor quantidade, e as espíritas, com participação muito reduzida (Silva Junior, 2015).

Os idosos declaravam a importância do momento dos encontros promovidos pelas igrejas para eles e que, após saírem da prisão, permaneceriam na religião, pois é ela que está lhes possibilitando ter força para viver e a fé em Deus é uma forma de suportar a prisão.

Penso que Jesus que vem cuidando de mim aqui, se não fosse Ele, já teria morrido. (IE $-16)$
Inferimos diante disso que as religiões dentro das prisões têm uma relevância social e são perpetuadas por uma memória que, apesar de recente dentro das prisões, uma vez que data da década de 1970/1980 (Quiroga, 2012), tem crescido de forma rápida e transmitida a todos que ali adentram por meio de uma memória de grupos, não só dos grupos religiosos, mas também através dos próprios presos, que trabalham na conversão do outro.

\section{O que esperam após saírem da prisão}

De forma genérica, os idosos mostraram-se bastante otimistas em relação do que será a vida após saírem da prisão, sendo a família a maior estimuladora, como poderá ser confirmado nas três narrativas abaixo; entretanto, sabem da realidade que enfrentarão extramuros, das dificuldades de reinserção e socialização, tendo em vista que os estigmas são construídos socialmente e mantidos por uma memória social (Halbwachs, 2003).

Meu futuro é incerto... Não consigo pensar direito em um futuro. Não sei o que vem por aí... Só Deus mesmo. Mas, se eu conseguir sair daqui vivo, a primeira coisa que penso em fazer é pegar meu filho... Me arrependo muito e sei que isso não traz a 
minha mulher de volta, mas quero que meu filho tenha orgulho de mim, do que eu fui e do que serei para ele. (IE-20)

A reinserção social, como já mencionada brevemente, é uma das maiores dificuldades que os egressos têm enfrentado e que o Estado tem para resolver, apesar de alguns empenhos percebidos. Quando se trata de jovens, o maior problema está relacionado ao emprego e à baixa escolaridade, esta, uma realidade comum dos presos no Brasil, mas, quando estamos diante da realidade de idosos, possivelmente, outros desafios serão enfrentados, em especial, a reinserção na sociedade e na família, principalmente pelos tipos de crimes cometidos e os problemas de saúde que foram intensificados na prisão.

$\mathrm{Na}$ verdade, para qualquer indivíduo que sai da prisão, os desafios da integração serão inúmeros. No Brasil, a reinserção social dos presos é uma tarefa desafiadora, pois, apesar de descrito na LEP brasileira, no Art. 10, que "a assistência ao preso e ao internado como dever do Estado objetiva prevenir o crime e orientar o retorno à convivência em sociedade, estendendo-se esta ao egresso" e ainda prevê assistência social, material, psicológica, de saúde, educacional, jurídica e religiosa, a sua efetivação tem enfrentado desafios concretos (Brasil, 1984).

Entretanto, em meio ao preconizado em lei, a reinserção ainda se encontra distante de ser concretizada. Essa assistência prevista na LEP enfrenta desafios estruturais, humanos e políticos. Além disso, está relacionada a algo que torna mais complexa a reintegração do preso na sociedade, que é a questão da memória e RS, a qual é carregada de preconceitos e estigmas frente aos presos.

Para tanto, entendemos que, além de outros fatores singulares, as relações familiares e sociais, bem como a forma como a sociedade caracteriza uma pessoa que acabou de sair da prisão, têm um papel importante na desistência do crime e na sua reinserção social, pois estão intimamente ligados à reintegração social e econômica, ligada às perspectivas de reentrada $\mathrm{e}$ reintegração (Harding, 2015).

Destarte, frente ao breve exposto, a esperança apresentada nas narrativas dos idosos está intimamente relacionada aos aspectos aqui colocados, visto que, não somente nos trechos destacados, mas durante todo o percurso do estudo, percebemos a vontade e, ao mesmo tempo, a certeza de serem aceitos e voltarem a uma vida tida como normal, com trabalho, convívio e aceitação, porém permanece o 
medo da volta, dos estigmas construídos e da recusa por parte da sociedade, da não aceitação.

\section{Considerações finais}

A trajetória de vida de idosos encarcerados antes e na prisão preserva a constituição família. Ela se mantém porque as experiências que são simbolizadas têm, como referências, definições cristalizadas socialmente, ancoradas por quadros sociais de memórias que permanecem, uma vez que continuam vivas nos grupos e são permanentemente mantidas.

Os resultados extraídos das memórias revelaram que há uma insatisfação geral dos idosos frente ao ambiente na prisão. Foi evidenciado que o idoso é retirado do convívio com a sociedade e experenciam com pessoas alheias o seu convívio no ambiente da prisão, sendo este inadequado à vida humana, inóspito, insalubre, com alimentação e locais para o descanso inapropriados, pouco ou nenhum acesso ao banho de sol, enfim, com condições mínimas de sobrevivência.

Em meio às recordações do passado, os resultados revelaram que há uma memória presentificada dos fatos relacionados ao crime que está interRev. Polis e Psique, 2021; 11(3): 138 - 159 relacionada em um contexto social construído de particularidades e complexidades. Nas narrativas foram vistos tipos de crimes que chocam a sociedade, como aqueles relacionados à violência contra mulher e à violência sexual, principalmente os pertinentes à criança e ao adolescente.

Destacamos que o ambiente da prisão, por si só, é favorável à violência, seja ela física e/ou psicológica, o que fere os direitos humanos. Vimos também que a violência que esses idosos sofrem na prisão é reflexo de situações vivenciadas fora dela. Notamos que a participação em grupos de convivência e a religião são, para os idosos, formas de manutenção da serenidade, capacidade de adaptação, redução de sofrimento e construção de vínculos sociais.

Por fim, os resultados deste estudo sinalizam para a necessidade de mais estudos sobre a temática, especialmente por pesquisadores da área da saúde, focando tanto na realidade da Bahia, quanto do Brasil, para que, assim, as multifaces dessa problemática anunciada possam ser aos poucos desvendadas, buscando intervenções eficazes e a instauração de mudanças, bem como um melhor conhecimento, visualização e divulgação sobre o tema. 


\section{Referências}

Acosta, D.F. et al. (2015). Violência contra a mulher por parceiro íntimo: (In)visibilidade do problema. Revista Texto Contexto Enfermagem, 24 (1), 121-7.

Almeida, M.V. (2009). Violência conjugal e álcool: (in)existência de uma relação causal? Universidade de Coimbra, Portugal. Disponível em: https://estudogeral.sib.uc.pt/handle/10 316/14286> Acesso em: 14 de março de 2018

Bardin, L. (2015). Análise de conteúdo. Lisboa, Portugal: Edições 70.

Bartlett, F.C. (1995). Remembering: a study in experimental and social psychology. Cambridge: Cambridge University Press.

Barufaldi, L.A. et al. (2017). Gender violence: a comparison of mortality from aggression against women who have and have not previously reported violence. Ciência \& Saúde Coletiva, 22 (9), 2929-2938.

Brasil. Código Penal. Decreto-lei no 2.848, de 7 de dezembro de 1940. Rio de Janeiro: Presidência da República Casa Civil Subchefia para Assuntos Jurídicos. Disponível em: http://www.planalto.gov.br/ccivil_03/d ecreto-lei/Del2848.htm. Acesso em: 29 de julho de 2017.

Brasil. Lei de Execução Penal. Lei 7.210 de 11 de julho de 1984. Disponível em:

http://www.planalto.gov.br/ccivil_03/ LEIS/L7210.htm. Acesso em 29 de julho de 2016.
Cabral, L.R., \& Silva, J.L. (2010). O trabalho penitenciário e a ressocialização do preso no Brasil. Revista do CAAP, 157-184.

Caculo, A.M. O trabalho infantil. 2017. Disponível em:

$<$ https://ilpi.org/wpcontent/uploads/2017/06/O-trabalhoinfantil.pdf $>$ Acesso em: 28 de abril de 2018.

Cnpcp, Conselho Nacional de Política Criminal e Penitenciária. Resolução ${ }^{\circ}$ 14, de 11 de novembro de 1994. Disponível em: http://www.crpsp.org.br/interjustica/pd fs/regras-minimas-para-tratamentodos-presos-no-brasil.pdf> Acesso em: 19 de fevereiro de 2018.

Cronemberger, I.H.G.M., \& Teixeira, S.M. (2018). Famílias Vulneráveis como expressão da questão social, à luz da política de assistência social. RevistaEletrônica Informe Econômico, 1(1).

Cruz, V.D. et al. (2016). Drug consumption among elderly and harm reduction: a reflection from the complexity. Escola Anna Nery, 20(3).

Cunha, T.R.A. (2007). O preço do silencio: mulheres ricas também sofrem violência. Editora UESB, $1^{\text {a }}$ edição, Vitória da Conquista, BA.

Cunningham, A.N.N. (2001). Forgotten families - the impacts of imprisonment. Australian Institute of Family Studies. Family Matters, 59 Winter.

Depen, Ministério da Justiça. Levantamento Nacional De 
Informações Penitenciárias Infopen2014.

Fals-Stewart, W. (2003). The occurrence of partner physical aggression on days of alcohol consumption: a longitudinal diary study.J ConsultClinPsychol., 71 (1), 41-52.

Fentress, J., \& Wickham, C. (1992). Memória Social.Lisboa, Portugal: Editora Teorema.

Ferreira, F.F.U., \& Andrade, S.A. (2015). Crise no Sistema Penitenciário Brasileiro: capitalismo, desigualdade social e prisão. Revista Psicologia, Diversidade e Saúde, 4 (1), 116-129.

Foucault, M. (2013). A Verdade $e$ as Formas jurídicas. Rio de Janeiro, Brasil: Nau Editora.

Foucault, M. (2009). Vigiar $e$ punir.Petrópolis, Brasil: Editora Vozes.

Gomes, N.S.,Kölling, G., \&Balbinot, R.A.A. (2015). Violações de direitos humanos no presídio do roger, no estado da paraíba. Revista do Direito Sanitário,16(1), 39-58.

Halbwachs, M. (2013). A memória coletiva. Trad. Beatriz Sidou. São Paulo, Brasil: Centauro.

HALBWACHS, M. (1991). Fragmentos da la Memoria Coletctiva. Revista de Cultura Psicológica. UNAMFaculdad de psicologia, 1(1).

Halbwachs, M. (1994). LesCadresSociaux de laMémoire. Paris, França: Albin Michel.
Halbwachs, M. (2004). Los Marcos Sociales de La Memoria. Universidad de Concepción de Caracas. Universidad Central de Venezuela. Barcelona, Espanha: Anthropos Editorial.

Harding, D.J. et al. (2018). Making Ends Meet After Prison. HHS Authormanuscript. USA.

Laranjeira, R.,Duailibi, S.M., \&Pinsky, I. (2005). Álcool e Violência: a psiquiatria e a saúde pública. Revista Brasileira Psiquiatria, 27 (3), 176-7.

Machado, V.G. (2013). Análise sobre a crise do sistema penitenciário e os reflexos do fracasso da pena de prisão.Derecho y Cambio Social. Lima Peru.

Marin, M.J.S. et al. (2012). Compreendendo a história de vida de idosos institucionalizados. Revista Brasileira Geriatrologia Gerontologia, 15 (1), 147-154.

Minayo, M.C.S., \& Constantino, P. (ORG). (2015). Deserdados sociais: condições de vida e saúde dos presos do estado do Rio de Janeiro. Rio de Janeiro, Brasil: Editora Fiocruz.

Novaes, R.R. (2012). Religiões atrás das grades: olhar dos pesquisadores. Instituto de Estudos da Religião. Religiões e Prisões. Comunicações do Iser, 61,

Onofre, E.M.C. (2016). A prisão: instituição educativa? Caderno Cedes, 36 (98), 43-59.

Opas. (2015). Organização Pan-Americana de Saúde. Organização Mundial de Saúde. Violência contra a mulher. 
Estratégia e plano de ação para o reforço do sistema de saúde para abordar a violência contra a mulher. 54. ${ }^{\circ}$ Conselho Diretor $67 .{ }^{\text {a }}$ Sessão do comitê regional da OMS para as américas.

Pecora, A.R., \& Sá, C.P. de. (2008). Memórias e representações sociais da cidade de Cuiabá, ao longo de três gerações. Psicologia Reflexão Crítica, 21 (2), 319-325.

Pillon, S.C., Cardoso, L., Pereira, G.A.M., \& Mello, E. (2010). Perfil dos idosos atendidos em um centro de atenção psicossocial - álcool e outras drogas. Escola Anna Nery, 14 (4), 742-748.

Prodanov, C.C., \& Freitas, E.C. Metodologia do trabalho científico: Métodos e Técnicas da Pesquisa e do Trabalho Acadêmico. Hamburgo, Brasil: Editora Feevale.

Quiroga, A.M. (2012). Religiões e Prisões no Rio de Janeiro: presença e significados. Religiões e Prisões. Comunicações do Iser, 61.

QrsInternational. (2013). NVivo 11 for Windows

GettingStartedGuide.Doncaster, AUS: QRS InternationalPty Ltd.

Sarti, C.A. (2004). A família como ordem simbólica. Psicologia USP, 15, 3, 1128.

Sequeira, V.C. (2005).Vidas abandonadas: crime, violência e prisão. Programa de Estudos de Pós-graduação em Ciências Sociais. [tese] Pontifícia Universidade Católica. São Paulo.

Soares Filho, M.M., \& Bueno, P.M.M.G. (2016). Demography, vulnerabilities and right to health to Brazilian prison population. Ciência \& Saúde Coletiva, 21(7), 1999-2010.

Zappe, J.G., \& Dias, A.C.G. (2012). Violência e fragilidades nas relações familiares: refletindo sobre a situação de adolescentes em conflito com a lei. Estudos de Psicologia, 17 (3), 389395.

Pollyanna Viana Lima é enfermeira e doutora em Memória: Linguagem e Sociedade pela Universidade Estadual do Sudoeste da Bahia. É também professora da Faculdade Independente do Nordeste (FAINOR).

E-mail: polly_vl@yahoo.com.br

ORCID:https://orcid.org/0000-0003-1277$\underline{7661}$

Tatiane Dias Casimiro Valença é fisioterapeuta e doutora em Memória: Linguagem e Sociedade pela Universidade Estadual do Sudoeste da Bahia. É também professora da Universidade Estadual do Sudoeste da Bahia (UESB).

E-mail:tativalenca26@gmail.com

ORCID:https://orcid.org/0000-0002-2746$\underline{5620}$

Alessandra Souza de Oliveira é doutoranda e mestra em Memória: Linguagem e Sociedade na Linha de Pesquisa em Memória, Envelhecimento e Dependência Funcional pela Universidade Estadual do Sudoeste da Bahia-UESB. É também bacharel em Enfermagem pela Universidade de Marília-UNIMAR.

E-mail:alessandraoliveira@ fainor.com.br ORCID:https://orcid.org/0000-0001-9250705X

Luciana Araújo dos Reis é fisioterapeuta e doutora em Ciências da Saúde pela 
Universidade Federal do Rio Grande do Norte. É também professora da

Universidade Estadual do Sudoeste da Bahia (UESB).

E-mail:Luciana.araujo@uesb.edu.br ORCID:https://orcid.org/0000-0002-0867$\underline{8057}$

Submissão: 01/09/2021

$1^{o}$ avaliação: 13/09/2021

Aceite: $11 / 10 / 2021$ 